First publ. in: Experimental Gerontology 43 (2008), 7, pp. 605-614

\title{
Poly(ADP-ribose) polymerase activity in different pathologies - The link to inflammation and infarction
}

\author{
Sascha Beneke* \\ University of Konstanz, Molecular Toxicology Group, Universiteatsstr. 10, Box X911, 78457 Konstanz, Germany
}

Keywords:

Poly(ADP-ribose) polymerase

Inflammation

NFKB

Ischemia-reperfusion injury

Cell death

Reactive oxygen species

\begin{abstract}
A B S T R A C T
DNA repair and aging are two phenomena closely connected to each other. The poly(ADP ribosyl)ation reaction has been implicated in both of them. Poly(ADP ribose) was originally discovered as an enzymatic reaction product after DNA damage. Soon it became evident that it is necessary for regulation of different repair pathways. Also, evidence accumulated that poly(ADP ribose) formation capacity is at least corre lated with the life span of mammalian species. As a NAD ${ }^{+}$consuming process, poly(ADP ribosyl)ation can lead to cell death by energy depletion. This finding opened the area for investigation of poly(ADP ribose) polymerase activity and polymer formation in pathologies. This review provides an introduction into the wide and complex field of poly(ADP ribosyl)ation in different pathologies with regards of cell death reg ulation, inflammation and resulting tissue damage.
\end{abstract}

\section{Introduction}

Understanding the molecular mechanisms leading to diseases is a prerequisite to develop better treatments to diminish the symp toms or to cure the disease. Aging is the declining ability of an organism to respond in an adequate way to any kind of stress. This includes external stresses like harmful chemicals, radiation or pathogens as well as internal stresses like nitric oxide (NO) metab olites or reactive oxygen species (ROS). Inappropriate functioning of DNA repair processes has been implicated in many hereditary diseases like xeroderma pigmentosum, ataxia telangiectasia, Fanconi anemia, Li Fraumeni syndrome or hereditary nonpolyposis colon cancer [for recent reviews, see (Fousteri and Mullenders, 2008; Garcia and Benitez, 2008; Lavin, 2007; Rustgi, 2007; Shuck et al., 2008; Zambetti, 2007)].

But also an intact system can lead to pathologies, as in the case of DNA damage activated poly(ADP ribose) polymerases 1 and 2 . Here, overstimulated enzymatic activity depletes the cellular en ergy pool, leading to cell death (Berger et al., 1983; Sims et al., 1983). To add another layer of complexity, at least PARP 1 also reg ulates the NFKB dependent inflammation response, connecting the pathogen defense system to DNA repair [for review, see (Hassa and Hottiger, 2002)].

Poly(ADP ribosyl)ation is an immediate reaction of mammalian cells to genotoxic stress, described first in the 1960s (Chambon

\footnotetext{
* Tel.: +49 7531 884067; fax: +49 7531884033 .

E-mail address: sascha.beneke@uni-konstanz.de.
}

et al., 1963). The substrate $\mathrm{NAD}^{+}$is cleaved into nicotinamide and an ADP ribosyl residue, which is used, in successive reaction cycles, for the synthesis of ADP ribose polymer chains that consist of up to 200 units and also display branching. This highly energy demanding reaction is catalyzed by a family of enzymes called poly(ADP ribose) polymerases (PARPs). The human genome com prises 18 (candidate) genes that (may) encode PARP family mem bers (Ame et al., 2004). Only a few of them are well characterized and just two are known to be stimulated by DNA strand breaks, i.e., PARP 1 and PARP 2. Their product, poly(ADP ri bose) (PAR), is involved in many aspects of cellular functions, not only regulating DNA repair (especially base excision repair and double strand break repair), but also maintaining genomic integ rity by regulating mitosis and spindle organization as well as telo mere stability, thus preventing cancer formation [for a recent review regarding genomic stability and aging see (Beneke and Bur kle, 2007)]. After genotoxic stress, PARP 1 is responsible for roughly $90 \%$ of PAR formed, as evident from Parp 1 knockout (KO) animals, which show a residual $10 \%$ polymer production after chal lenge (Shieh et al., 1998). Knocking out either of these two PARPs leads to enhanced sensitivity against genotoxic agents in mice as evidenced by increased genomic instability and cell death upon exposure to DNA damaging agents (de Murcia et al., 1997; Schrei ber et al., 2002; Menissier de Murcia et al., 2003), underscoring the importance in regulating repair functions by these enzymes. The concept of PARP activity dependent cell death by energy depletion has been first published by Nathan Berger and colleagues (Berger et al., 1983; Sims et al., 1983). Inhibition of PARPs leads to 
increased genomic instability after genotoxic stress. Overexpres sion of PARP 1 and subsequent stimulation of the enzymatic activ ity leads to enhanced cell death, but surviving cells show less genomic instability. Thus, the activity of PARP 1 and maybe also of PARP 2 has to be tightly regulated to produce an appropriate le vel of polymer formation, compatible with cell survival and main taining genomic stability [for review, see (Bürkle, 2001)].

The connection between PARP activity dependent necrosis and PARP regulated inflammation can induce a self amplifying cycle of cell death and immune response, subsequently leading to in creased tissue damage. Focusing on this vicious circle, selected publications relating to different pathologies will be discussed below.

\section{Poly(ADP-ribose) metabolism}

As mentioned above, most eukaryotic cells respond to genotoxic insult with the formation of an unusual polymer termed poly(ADP ribose) or PAR. The substrate for this reaction is the reduction equivalent nicotinamide dinucleotide $\left(\mathrm{NAD}^{+}\right)$, an important elec tron acceptor in many metabolic pathways (for example, glycoly sis, Krebs cycle, $\beta$ oxidation). PAR production takes place mainly in the nucleus and cytoplasm, but some reports show also polymer formation within mitochondria [for review, see (Scovassi, 2004)]. Baseline levels of PAR in mammalian cells are quite low and, be sides the nucleus, localized to confined areas like spindle apparatus (Chang et al., 2005; Yeh et al., 2006b), telomeres (Dantzer et al., 2004; O'Connor et al., 2004; Smith et al., 1998), and trafficking ves icles (Chi and Lodish, 2000; Yeh et al., 2006c). After DNA damage, polymer levels in the nucleus raise several hundredfold by the en hanced activity of PARP 1 and PARP 2. Both are so far the only members of the PARP family that have been shown to bind to DNA strand breaks and are stimulated in this way. Accumulation of PAR is counteracted by the activity of the catabolic enzyme poly(ADP ribose) glycohydrolase (PARG). Here, a single gene serves by alternative splicing as template for the production of several protein isoforms located in different cellular compartments (Meyer Ficca et al., 2004). Immediately after initiation of PAR for mation, PARG activity degrades nascent polymers, longer ones by a fast endonucleolytic, shorter ones by a slow exonucleolytic attack, resulting in monomeric ADP ribose [for review, see (Bonicalzi et al., 2005; Cuzzocrea and Wang, 2005)]. Therefore, the detectable amount of polymer reflects the actual balance of production and degradation. DNA repair and re sealing of the gap stops PAR production.

\section{PARP activity-dependent cell death}

As stated in the previous section, polymer production is accom panied by PARG dependent degradation. Upon DNA damage, PARP 1 and PARP 2 bind to strand breaks and synthesize PAR. With the ongoing synthesis and degradation cycles, large amounts of $\mathrm{NAD}^{+}$can be consumed, dependent on the severity of the geno toxic insult. The higher the PARP activity either by increased DNA damage or by PARP overexpression, the more NAD ${ }^{+}$is cleaved. In an attempt to re synthesize this important energy carrier to meet the demand of metabolic processes, cells use 34 ATP for each $\mathrm{NAD}^{+}$molecule. If DNA damage is too severe, energy levels (NAD ${ }^{+}$ and subsequently ATP) drop fast and cells die from necrosis. Rup tured cells release their content into the environment, increasing the load of reactive oxygen species (ROS). In multicellular organ isms, this can lead to a self amplifying DNA damage response, with cell death spreading to the surrounding tissue. Depending on the nature of the agent used and the origin of the affected cells, an other pathway of death can ensue. For example, in fibroblasts, se vere activation of PARPs by alkylating agents leads to massive PAR production (Yu et al., 2002). Free polymer, probably released by the endonucleolytic activity of PARG, is transported to the mitochon dria by an unknown mechanism, maybe involving a transporter protein. Here, it leads to the release of apoptosis inducing factor (AIF) from the inter membrane space. AIF is a FAD containing pro tein with homology to oxido reductases. It induces caspase inde pendent apoptosis upon release from mitochondria [for review, see (Cregan et al., 2004)]. It is unclear if poly(ADP ribose) binds to a receptor on the outer mitochondria membrane and thus trig gers opening of specific pores, or if it traverses the membrane itself and leads to rearrangements within the mitochondria. After release from mitochondria, AIF translocates into the nucleus and induces high molecular weight fragmentation of DNA ( $50 \mathrm{~kb})$ by activation of an unidentified nuclease, as AIF itself has no detectable nuclease function. These are the first steps in a caspase independent apop totic pathway. Although not firmly proven, several lines of evi dence point to this specific mechanism. First, PARP inhibition or Parp 1 knockout severely impairs the release of AIF from mito chondria (Yu et al., 2002). Vice versa, activation of PARP or trans fection of free polymer into susceptible cells leads to AIF triggered apoptosis (Yu et al., 2006).

Thus, there are two mechanisms indirectly linked to the repair function of PARP 1 and PARP 2: necrosis by energy depletion and apoptosis by AIF release from mitochondria. This can be described as the dark side of the Janus like nature of repair PARPs, which are usually beneficial for the cell's survival.

\section{PARP activity in sepsis and inflammation}

In sepsis, the most feared pathophysiological reaction is the dis turbance of the cardiovascular system with vasodilation and loss of fluid from the vascular system into the tissue, for example, induced by increased $\mathrm{NO}^{*}$ concentrations. The subsequent drop in blood pressure and diminished supply of tissues leads to systemic circu latory failure and death of the patient. What is a good and effective mechanism fighting local infections is harmful if the reaction can not be controlled properly.

Evidence that PARP 1 is not only involved in DNA repair, but also in septic shock came from inhibitor studies. In the mid 90s of the last century several papers were published showing a pro tective effect of PARP inhibition after treatment of mammalian cells with microbial substances like Escherichia coli lipopolysaccha ride (LPS) and zymosan from Saccharomyces cerevisiae (Cuzzocrea et al., 1997b; Szabo et al., 1996; Zingarelli et al., 1996). This was re ferred to the induction of reactive oxygen species (ROS), including peroxynitrite, by these compounds and subsequent DNA damage. It was shown in 1997 that the induction of pro inflammatory cyto kines by LPS treatment of macrophages could be prevented by PARP inhibition (Hauschildt et al., 1997). Likewise, Szabo and col leagues reported an anti inflammatory effect of PARP activity sup pression either by Parp1 gene knockout or pharmacological inhibition (Szabo et al., 1997). Also, LPS treatment of rats led to im paired endothelial functions, which could be alleviated by admin istering the PARP inhibitor 3 aminobenzamide (3AB) (Szabo et al., 1996). Detailed analysis of knockout mice showed that genetic ablation of PARP 1 protected from endotoxic shock (Oliver et al., 1999). LPS challenged wild type mice had elevated TNF $\alpha$ serum levels and increased expression of iNOS with subsequent survival rate of only $10 \%$. In contrast, only $10 \%$ of the Parp 1 knockout ani mals died. In cell culture it could be shown that a decreased tran scriptional activity of NFKB is responsible for this effect. The translocation of NFKB after the stimulus was not impaired, so the proximal steps of intracellular signaling cascade were still intact. In a porcine model of sepsis, bacterially inoculated pigs showed 
better cardiovascular performance and higher survival rates when treated with the PARP inhibitor PJ34 (Goldfarb et al., 2002). Like wise, other publications reported beneficial effects on selected or gans (such as liver) as well as systemic improvements after application of PARP inhibitors alone (Ivanyi et al., 2003; Jagtap et al., 2002) or in combination with inhibitors of nitric oxide pro duction (Stehr et al., 2003), probably additionally reducing DNA damage and vasodilation. Serum from septic patients induced mitochondrial dysfunction in an endothelial cell system, and this was prevented by administering $3 \mathrm{AB}$ (Boulos et al., 2003). Suppres sion of inflammation is a constant feature in Parp1 knockout mice or PARP inhibition after challenge [see also (Hasko et al., 2002; Veres et al., 2003)], and pan PARP inhibitors seem to be more effec tive than Parp1 KO, pointing to the fact that not only PARP 1 is in volved in the pathology, but probably also PARP 2 .

In conclusion, blocking PARP activity reduces the cell death resulting from energy depletion. Also, it dampens the inflamma tory response of immune cells and diminishes the affected (necro tic) area by impairing NFKB dependent transcription. Suppressed iNOS induction leads to less $\mathrm{NO}^{*}$ and less ongoing DNA damage. Diminished $\mathrm{NO}^{*}$ production reduces also vasodilation, suppressing this part of the response to sepsis [for review, see (Szabo, 2007)].

\subsection{PARP activity and inflammation}

PARP inhibition prevents inducible nitric oxide synthase (iNOS) induction by tumor necrosis factor alpha (TNF $\alpha$ ) in fibroblasts (Hauschildt et al., 1992) or by interferon gamma (IFN $\gamma$ ) in vascular smooth muscle cells (Szabo et al., 1996). Also, inflammation and neutrophil adhesion was reduced in experimentally induced peri tonitis (Szabo et al., 1997). Quickly, it became clear that the tran scriptional activity of the master regulator of inflammatory reactions, nuclear factor kappa $B$ (NFKB), depends on the poly( ADP ribosyl)ation system. Many cytokines like TNF $\alpha$, MIP1 $\alpha$, IL1 $\beta$ and IFN $\gamma$ as well as inducible nitric oxide synthase (iNOS) and adhesion molecules are not or only marginally induced without PARP 1 activity (Haddad et al., 2006; Jijon et al., 2000; Mazzon et al., 2002; Su et al., 2007; Zingarelli et al., 1998). After induction, iNOS produces nitric oxide (NO*) through enzymatic oxidation of $\mathrm{L}$ arginine. $\mathrm{NO}^{*}$ is not only an important mediator of vascular dila tion, but also as metastable radical involved in DNA damage. NO reacts with superoxide anion $\left(\mathrm{O}_{2}{ }^{*}\right)$ to form peroxynitrite (ONOO ). Superoxide dismutase (SOD) converts $\mathrm{O}_{2}{ }^{*}$ into oxygen and hydrogen peroxide $\left(\mathrm{H}_{2} \mathrm{O}_{2}\right)$, which in turn is detoxified by cat alase or glutathione. In the Fenton reaction, $\mathrm{H}_{2} \mathrm{O}_{2}$ together with $\mathrm{Fe}^{2+}$ leads to formation of hydroxyl radicals $\left(\mathrm{OH}^{*}\right)$. All four mole cules $\left(\mathrm{O}_{2}{ }^{*}\right.$, ONOO $\left., \mathrm{H}_{2} \mathrm{O}_{2}, \mathrm{OH}^{*}\right)$ belong to the family of reactive oxygen species, which are able to induce directly or indirectly damage in DNA. DNA strand breaks in turn activate repair PARPs and this can cause energy depletion, leading to necrotic cell death. Necrosis triggers an inflammation reaction via NFKB and iNOS induction with increased load of $\mathrm{NO}^{*}$ and subsequently more DNA damage. Released cytokines recruit immune cells like neutro phils, macrophages and cytotoxic T cells. These in turn release ROS or lytic proteins like perforins, additionally damaging cells. The interplay between NFKB dependent immune response and PARP 1 dependent energy depletion further increases of the necrotic area [for review, see (Szabo, 2006)].

\section{PARP activity and stroke}

Wallis and colleagues reported that ADP ribosylation inhibitors as well as inhibitors of NO* production prevented nitric oxide in duced injury in hippocampus slices (Wallis et al., 1996, 1993). Soon after, the Dawson laboratory reported a beneficial effect of PARP 1 inhibition or knockout in mice after $N$ methyl D aspartate (NMDA) induced toxicity or ischemia reperfusion (Eliasson et al., 1997). Similar results were published by Endres and colleagues (Endres et al., 1997). Deleting PARP 1 protected from NMDA induced toxic ity in brain cell culture and from the deleterious effects of middle cerebral artery occlusion (MCAO) in mice, mainly reducing the size of the infarcted region. Likewise, PARP inhibitors showed a pro found protective effect in cortical brain cell cultures, superior to the genetic PARP 1 ablation. Additionally, Endres and colleagues (Endres et al., 1997) showed that $3 A B$ reduced the infarcted region after ischemia reperfusion injury to the same extend as PARP 1 knockout. Also, a report showed that PARP inhibition in a rat model of focal cerebral ischemia reduced the size of the infarcted area (Takahashi et al., 1997). Genetic deletion of nNOS prevented PAR formation after ischemia, and peroxynitrite, but not NO donors, were effective in stimulating PARP activity in glioma cells (Endres et al., 1998a). Many subsequent studies showed protection against ischemia reperfusion injury with different PARP inhibitors like $\mathrm{INH}_{2} \mathrm{BP}$ (Endres et al., 1998b), DPQ (Takahashi et al., 1999) or PJ34 (Abdelkarim et al., 2001). In subsequent cell culture studies, PARP activity was reported to promote NFKB DNA binding in LPS or INF $\gamma$ exposed microglia, thus leading to activation and neuro toxicity. PARP inhibitors applied $1 \mathrm{~h}$ before the stimulus reduced the expression of NFKB targets like iNOS, IL1 $\beta$ and TNF $\alpha$ as well as neuronal cell death (Chiarugi and Moskowitz, 2003). Thus, PARP inhibition not only impacts directly on cells, but regulates the tis sue response to insults, i.e., stimulation of microglia and subse quent neuronal cell death. Likewise, PARP inhibition before global cerebral ischemia preserved the functionality of the blood brain barrier with reduced edema, attenuated permeability increase and reduced neutrophil infiltration (Lenzser et al., 2007). In many publications, researchers pre treated animals or cells with PARP inhibitors before ischemia or analogous in vitro conditions, which would not be a realistic scenario for emergency medical aid after stroke. But some reports show beneficial effects of inhib iting PARP even after ischemia reperfusion injury. For example, Hamby and colleagues reported that administration of PJ34 to rats $8 \mathrm{~h}$ after forebrain ischemia led to near complete suppression of microglia activation even 5 days after ischemia and to $84 \%$ reduc tion of neuronal cell death in the CA1 region of the hippocampus (Hamby et al., 2007). Thus, even late stage PARP inhibition may have a protective function after brain ischemia reperfusion injury [for a recent review, see (Chiarugi, 2005)].

\section{PARP activity and diabetes}

Diabetes is the inability to keep blood glucose level in a physi ological (low) range, either by a diminished production of insulin as a consequence of pancreatic $\beta$ cell destruction (Type I) or by lack of responsiveness to insulin (Type II). But the resulting long term effects are far more dangerous than acute hyperglycemia itself. Chronic hyperglycemia damage the endothelial cells in the vessels, and actually most medical complications result from pathological alterations of the vascular system, leading to increased risk of blindness, infarction of brain and heart, kidney failure and im paired wound healing [for recent reviews, see Hartge et al., 2007; Hermans, 2007; Nicolls et al., 2007].

Isolated pancreatic islet cells were protected from cell death in duced by $\mathrm{NO}^{*}$ donors, if they were treated with nicotinamide or $3 A B$, two inhibitors of PARP activity (Kallmann et al., 1992; Radons et al., 1994). Radical scavengers like $N$ acetylcysteine, dihydroli poic acid, dimethylthiourea and citiolone were not effective. Inhi bition of PARPs diminished the concomitant $\mathrm{NAD}^{+}$loss and prevented PAR formation (Inada et al., 1995). Likewise, isolated $\beta$ cells from Parp1 knockout animals were protected from cell 
death induced by ROS (Heller et al., 1995). In diabetes experimen tally induced by application of the alkylating drug streptozotocin, Parp1 knockout mice turned out to be protected from $\beta$ cell loss and subsequent diabetes type I. Gene dosage seemed to be impor tant as Parp $^{+1}$ animals were partially protected (Pieper et al., 1999). Animals were also protected after changing the application of streptozotocin from a single high dose to multiple low dose injections, if PARP enzymes were inhibited or the Parp1 gene was disrupted (Mabley et al., 2001). Thus, repressing PARP activity di rectly inhibits islet cell loss and therefore prevents the onset of type I diabetes.

As mentioned earlier, hyperglycemia damages the endothelium, which results in major remodeling of vascular structure like arte riosclerosis [for review, see (Reusch and Draznin, 2007)].

The increased cellular damage induces also DNA strand breaks, which in turn activates PARP. Treatment of experimentally induced diabetes in rats or established diabetes in a genetic mouse model (non obese diabetes, NOD) with PARP inhibitors reduced oxidative stress markers (higher nitrotyrosine amount, PAR formation) (Il nytska et al., 2006; Pacher et al., 2002b), and reduced the elevated cell death in retinal endothelium (Zheng et al., 2007). Diastolic dys function of the heart and loss of endothelium dependent vasodila tion was significantly improved by PARP inhibitors (Pacher et al., 2002b). Administering the PARP inhibitor PJ34 even one week after onset of diabetes was effective despite persistent hyperglycemia. Rats with streptozotocin induced diabetes showed increased heart dysfunction and a larger infarcted area after myocardial ischemia reperfusion injury as well as higher mortality rates during reperfu sion. Blocking PARP activity with the inhibitor INO 1001 improved myocardial function in both groups. In diabetic rats, INO $1001 \mathrm{sig}$ nificantly lowered the mortality during the experiment (Xiao et al., 2004). The increase in nuclear AIF after ischemia reperfusion was prevented in both control and diabetic groups.

Therefore, potent PARP inhibitors reduce the clinical complica tions usually seen in diabetes and are good candidates for medical treatment. As a caveat: PARP inhibition has been shown to pro mote cancer formation under genotoxic stress (see Section 1). Like wise, due to the many cellular functions regulated by poly(ADP ribosyl)ation, very specific inhibitors have to be used in order to leave other PARPs unaffected [for review, see (Pacher and Szabo, 2005)].

In one study (Szabo et al., 2002a), Type II diabetic patients, per sons with a history of parental Type II diabetes, and normal healthy controls were monitored for the amount of basal poly(ADP ribose) in skin biopsies. Not only manifest Type II diabetes led to a higher polymer level, but also a parental history. Also, vascular reactivity and skin microcirculation was impaired in both groups.

Therefore, basal PAR levels might serve as a predictive marker for an increased risk to develop diabetes in future.

\section{PARP activity and intestinal injury}

Inflammatory diseases of the gut like Crohn's disease show a constant loss of intestine functionality, and large areas can become necrotic and have to be surgically excised to prevent additional amplification of the symptoms by the necrotic tissue. Usually, two chemical compounds are used to induce colitis in animals: tri nitrobenzene sulfonic acid (TNBS) and dinitrobenzene sulfonic acid (DNBS). Rats exposed to one of these show colonic erosion, ulcera tion, necrosis, neutrophil infiltration, apoptosis, elevated nitrotyro sine formation and activation of NFKB and downstream targets like ICAM 1 (Mazzon et al., 2002; Zingarelli et al., 2003). Application of PARP inhibitors before drug administration reduced all these symptoms. Even if the inhibitor is applied after damage induced by DNBS or ischemia reperfusion (IR) by occlusion of the splanch nic artery (Di Paola et al., 2005), the treatment was beneficial. The authors also showed an overall anti inflammatory effect with less PAR formation and infiltrating immune cells and a delay in clinical signs of the disease. Cuzzocrea and colleagues used occlusion of the splanchnic artery as a model to investigate the effect of $3 \mathrm{AB}$ on intestinal functionality parameters (Cuzzocrea et al., 1997a). Dur ing ischemia, no increase in fluorescence of the oxidation marker rhodamine was detected in plasma, but during reperfusion, fluo rescence markedly increased. This was blunted by administering of $3 A B$. Permeability of the intestine, nitrotyrosine amount and PARP activity was increased after ischemia reperfusion injury. $3 \mathrm{AB}$ treatment brought the values back close to control levels and decreased the mortality. Likewise, endothelial dysfunction and vascular hyporeactivity was improved by $3 \mathrm{AB}$. The overall tis sue damage was reduced by PARP inhibition.

In the mouse IL10 knockout model of inflammation, inflam matory markers like TNF $\alpha$, INF $\gamma$ and iNOS are highly elevated. Also, the intestine shows increased permeability, ulceration and the cellular energy balance is perturbed. Treatment with the PARP inhibitor 3 aminobenzamide for 14 days brought perme ability back to normal and reduced the levels of cytokines (Jijon et al., 2000). In the same genetic model, PARP 2 antisense oligo nucleotides proved to be effective (Popoff et al., 2002). This treatment also attenuated inflammation and restored permeabil ity. Thus, not only PARP 1 but also PARP 2 is involved in medi ating inflammation and tissue damage. The level of influence probably depends on the expression level of these two PARPs in the tissue examined. In summary, PARP inhibition proved to be very effective in suppression of tissue damage in colitis or ischemia reperfusion injury of the gut.

\section{PARP activity and liver injury}

Ischemia reperfusion injury and subsequent necrotic cell death in liver is a common side effect of liver resection. The effect of PARP inhibitors on liver damage either by ischemia reperfusion or after application of chemicals is controversial. Some reports showed protection (e.g., Chen et al., 2007; Szijarto et al., 2007). When rats are pre treated with the inhibitor PJ34, hepatic microcirculation is preserved and the cell death rates are lower (Szijarto et al., 2007). Also, the mode of death is shifted from necrosis to an increased amount of apoptosis. That the examination of only one organ is not enough to assess all effects of a treatment has been shown by Chen and colleagues (Chen et al., 2007). They reported that ischemia reperfusion of the liver leads not only to impaired func tion of the respective organ, but that, for example, the heart is also affected as shown by increased blood levels of cardiac troponin I, an established biomarker of myocardial damage. As inflammatory cytokines like TNF $\alpha$ as well as radicals were elevated, they hypoth esized that the systemic inflammatory response may damage also other tissues, i.e., the heart. Administering $3 \mathrm{AB}$ led to decreased in jury in both liver and heart.

The inhibitor 5 aminoisoquinolinone (5 AIQ) attenuated inflam mation response and cell death after ischemia reperfusion in mice (Khandoga et al., 2004). Increase of the cellular damage marker aspartate aminotransferase (AST) was inhibited, but not that of ala nine aminotransferase (ALT). Also, no protection against the post ischemic oxidative stress was observed and mortality rates between the two ischemia reperfusion groups (with and without inhibitor) were identical, although 5 AIQ administration prolonged survival.

Treatment of mice with high doses of the analgesic drug acet aminophen (AAP) leads to cell death induction of hepatocytes. $3 A B$ pre and post treatment protected against liver injury as de tected by diminished ALT release and DNA fragmentation (Cover et al., 2005). 5 AIQ application as well as Parp1 knockout showed 
no beneficial effects. Also, $3 \mathrm{AB}$ administration attenuated the liver injury in wild type as well as Parp1 knockout mice, suggesting PARP inhibition independent effects of $3 A B$ like reduced metabolic activation of AAP or antioxidant properties of $3 \mathrm{AB}$.

In contrast, older data showed no inherent antioxidant potential of $3 \mathrm{AB}$ and other PARP inhibitors. For example, the oxidant tert bu tyl hydroperoxide $(t \mathrm{BOOH})$ induces cell death in mouse fibroblasts and primary rat hepatocytes in two ways: one is sensitive to the administration of the antioxidant $N, N^{\prime}$ diphenylphenylene dia mine, the other is not (Yamamoto et al., 1993). The iron chelator deferoxamine prevented both death pathways. PARP inhibitors $3 \mathrm{AB}$ and benzamide prevented cell death in the presence, but not in the absence of $N, N^{\prime}$ diphenylphenylene diamine. The iron dependent induction of DNA single strand breaks was not affected by PARP inhibitors, but the accompanied loss of ATP and NAD ${ }^{+}$was. Thus, not the level of DNA damage but energy loss was dependent on PARP activity.

A publication from 1998 showed that the increase of serum AST and ALT after liver ischemia reperfusion injury in rats and rabbits was prevented by deferoxamine and the superoxide anion scaven ger tiron, but not by administering different PARP inhibitors, i.e., $3 \mathrm{AB}, 1,5$ dihydroxyisoquinoline ( 5 ISO) or 4 amino 1,8 naphthali mide (Bowes and Thiemermann, 1998). In contrast to that, the PARP inhibitor PJ34 has been shown to diminish effectively AST and ALT levels in serum after liver ischemia reperfusion injury in rats (Szijarto et al., 2007) and cell death was shifted from necrosis to apoptosis.

The above described discrepancies may depend on the different PARP inhibitors used in these two studies. But nevertheless, the re sults on PARP inhibition in hepatocytes and liver are conflicting and range from "protective" to "no specific effect". Most likely, the differences originate from the different systems used: mice vs. rats, in vivo vs. in vitro, ischemia reperfusion vs. chemical com pounds as well as different PARP inhibitors.

For a recent review on PARP activity and liver injury, see also (Gero and Szabo, 2006).

\section{PARP activity in lung pathologies}

Incubation of type II pneumocytes with hydrogen peroxide leads to a decrease in phosphatidylcholin production. Inhibition of PARPs with $3 \mathrm{AB}$ or nicotinamide before exposure rescued energy levels as well as phosphatidylcholin synthesis (Hudak et al., 1995). These data were confirmed by Ollikainen with regards to energy depletion (Ollikainen et al., 2000). Upon intratracheal administra tion of the DNA damaging agent bleomycin to mice, Genovese et al. could show that the two PARP inhibitors $3 \mathrm{AB}$ and 5 AIQ re duced the induced lung injury. Body weight loss and mortality rate was diminished, as were edema formation and tissue injury. Nitrotyrosine levels as a marker of oxidative stress as well as mye loperoxidase activity (neutrophil infiltration) were significantly re duced (Genovese et al., 2005).

The influence of PARP activity in lung during sepsis has been tested extensively. Parp1 knockout and, in part, the PARP inhibitor PJ34 diminished the expression of cytokines like TNF $\alpha$, IL $1 \beta$ (not with PJ34) and IL 6 as well as MIP 1a and MIP 2 (not with PJ34) after LPS instillation in mice. Hyperpermeability, neutrophil infil tration and tissue damage were also attenuated (Liaudet et al., 2002). This has been confirmed with niacinamide as a PARP inhib itor in LPS challenged rats (Kao et al., 2007). A combination of smoke inhalation and Pseudomonas aeroginosa instillation into sheep lungs led to decreased functionality and increased tissue damage. Administration of the PARP inhibitor INO 1001 improved parameters like hemorrhage, congestion and inflammation scores and lowered oxidative stress (Murakami et al., 2004). Similar re sults were obtained with LPS treated rabbits (Kiefmann et al., 2004). Here, $3 A B$ attenuated the expression of LPS induced iNOS and decreased oxidative stress as measured by lipid oxidation. In electromobility shift assays DNA binding of NFKB was enhanced in $3 \mathrm{AB} / \mathrm{LPS}$ treated animals compared to LPS only treated rabbits. But AP 1 binding was diminished. Maybe a combination of NFKB and AP 1 as transcription factors on target promoters is needed to induce inflammation in this experimental setup, whereas NFKB alone works as a pro survival factor. But nevertheless, PARP inhibi tion proved to be effective against sepsis induced changes in tissue homeostasis and inflammation also in lungs.

Ischemia of isolated perfused rat lungs led to an increase of pro inflammatory cytokines like TNF $\alpha$ and IL1 $\beta$, an increase in iNOS activity and subsequent elevated PAR formation with a drop in ATP levels (Su et al., 2007). Also, the lung weight, permeability and pulmonary artery pressure was increased. If the PARP inhibitor nicotinamide was given even $30 \mathrm{~min}$ after ischemia, the increase in all values was attenuated except for the pulmonary artery pres sure, which was in fact slightly higher. Occlusion (ischemia reper fusion) of both hind limbs of rats led to significant inflammation, oxidative stress (lipid peroxidation and nitrotyrosine formation) and edema in the lungs of these animals (Koksel et al., 2005). Administration of $3 \mathrm{AB}$ during ischemia reduced the elevated parameters close to normal levels.

Importantly, PARP inhibition proved to be effective also in asth ma models. In A549 human airway epithelial cells, hydrogen per oxide induced energy depletion, NFKB activation and IL 8 expression. This was prevented by administration of $3 \mathrm{AB}$. In the ovalbumin induced inflammation model in mice, Parp1 knockout as well as $3 A B$ suppressed airway inflammation and inhibited the expression of iNOS (Boulares et al., 2003). Using the same model, Virag and colleagues showed that PJ34 suppressed the expression of some, but not all allergen induced pro inflammatory molecules (Virag et al., 2004), as evident also from the publication from Liau det and colleagues (Liaudet et al., 2002). Expression of MIP $1 \alpha$, TNF $\alpha$ and IL 12, but not MIP 2, IL 5 and IL 13 could be downregu lated by PJ34 application. Also in a guinea pig model of ovalbumin induced asthma like reaction (Suzuki et al., 2004), PARP inhibitors $3 \mathrm{AB}$ and 5 AIQ were effective in suppressing oxidative stress (PAR and nitrotyrosine formation and lipid oxidation) and inflammation markers (TNF $\alpha$ release and neutrophil activation). Likewise, phe notypic parameters (cough and dyspnea) were improved. A very recent publication (Naura et al., 2008) determined the window of efficacy, during which PARP inhibition still proved to be effective. Previously, the group showed that pre administration of the novel inhibitor thieno[2,3 c]isoquinolin 5 one (TIQ A) before ovalbu min challenge prevented migration of eosinophils into the airway and suppressed the production of $\mathrm{T}$ helper type 2 dependent cyto kines (Oumouna et al., 2006). In the new publication, even one to six hours post application was effective. Surprisingly, suppression of the cytokines IL 4, IL 5 and IL 13 was more pronounced in the post application study. Therefore, PARP inhibition may provide a new and better strategy to treat allergy and asthma dependent inflammation [for review, see also [(Virag, 2005)].

\section{PARP activity and the cardiovascular system}

Diseases of the cardiovascular system are the major cause of death in industrial countries. Therefore, improving treatment will have a great impact on mortality rates and average life span.

In line with results from other tissues, PARP activation was de tected in cardiomyoblasts after challenge with oxidants like perox ynitrite and hydrogen peroxide, but not with NO donors ( $S$ nitroso $N$ accetyl DL penicillamine, diethyltriamine NONOate) (Gi lad et al., 1997). All chemicals induced reduction of mitochondrial 
respiration. Also, hypoxia and re oxygenation induced PAR forma tion. As expected, PARP activity was suppressed by addition of $3 A B$ and nicotinamide in all cases. In mouse Parp1 knockout fibroblasts, NO donors reduced mitochondrial respiration, whereas peroxyni trite and hydrogen peroxide did not. This supported the inhibitor treatment study. In conclusion, PARP activation depends on DNA damage induced by peroxynitrite or hydrogen peroxide. In this case, mitochondrial respiration failure can be rescued by PARP inhibitors, but not if reduction of mitochondrial respiration is achieved by NO donors, which do not activate PARPs.

In the same year, a study was published using PARP inhibition in ischemia reperfusion of rabbit hearts (Thiemermann et al., 1997). After occlusion and reperfusion of the left coronary artery, PARP inhibitors ( $3 \mathrm{AB}$, nicotinamide and 5 ISO) improved heart functionality and reduced infarct size, whereas structurally similar compounds ( 3 aminobenzoic acid and nicotinic acid), which did not inhibit PARPs, were not effective. Likewise, Zingarelli and col leagues reported similar effects in rats, and additionally elevated necrosis, neutrophil infiltration and nitrotyrosine formation with loss of ATP. $3 \mathrm{AB}$ diminished neutrophil activation and partially preserved myocardial ATP levels (Zingarelli et al., 1997). Also in a different animal model (pigs), $3 \mathrm{AB}$ application proved effective in reducing infarct size and contractile dysfunction (Bowes et al., 1998). As mentioned in the "inflammation" section (above), genet ic ablation of Parp1 in mice protected them from ischemia reper fusion injury and reduced expression of adhesion molecules (Zingarelli et al., 1998). A comparison between isolated perfused hearts of wt and Parp1 knockout mice after ischemia reperfusion (Pieper et al., 2000) showed in the genetically engineered animals less pronounced increase in $\mathrm{NO}^{*}$ and ROS and a less severe drop in $\mathrm{NAD}^{+}$and ATP levels. Infarct size in mice after global heart ische mia or after coronary artery occlusion in rats was diminished in knockouts and PARP inhibitor pre treated animals, respectively. As PAR formation was still increased after ischemia reperfusion in knockout mice, another PARP family member is likely also acti vated in this kind of injury, most probably PARP 2 . This is also sug gested by the fact that generally PARP inhibitor treatment seems to be slightly more effective in reducing infarct size than genetic Parp1 ablation. Using also the mouse Parp1 knockout model, it was shown that in addition to preserving functionality, INO 1001 attenuated heart remodeling after ischemia reperfusion injury (hypertrophy and formation of collagen in the hearts) as well as translocation of AIF into the nucleus (Xiao et al., 2005). When ischemia reperfusion was induced in pigs, inhibitor treatment during ischemia and continued during reperfusion also reduced in farct size and the heart showed a better functional recovery (Faro et al., 2002).

In a cardiomyoblast cell culture model, hypoxia with subse quent re oxygenation led to oxidative stress, PARP activation and a drop in energy metabolite levels (NAD ${ }^{+}$and ATP) (Fiorillo et al., 2006). Consequently, necrosis was the prevalent pathway of death. Additionally, AIF dependent apoptosis was increased. Administra tion of PJ34 attenuated the decrease in $\mathrm{NAD}^{+}$and ATP, probably due to reduced PAR formation. Inhibitor treatment was overall pro survival, with necrosis being affected (reduced) most. The cas pase independent apoptotic pathway was shifted to caspase dependent apoptosis. Thus, PARP inhibition does not only lead to cell survival, but also to modulation of the way cells die, shifting it from the pro inflammatory necrosis to the less harmful apoptosis.

Inhibition of poly(ADP ribose) polymerases is also effective in a chronic heart failure model (Pacher et al., 2002a). The left anterior descending coronary artery was ligated in rats and stress parame ters as well as functionality were tested. In controls, nitrotyrosine and PAR levels were increased, the performance of the left ventri cle was reduced and relaxation impaired (measured ex vivo). PJ34 reduced the amount of PAR as expected, but had no significant im pact on nitrotyrosine formation. Thus, it was not the initial damage (nitrotyrosine level), but the activity of PARPs (polymer amount) that was suppressed. The functionality parameters measured were improved, i.e., left ventricle performance and relaxation.

Vasorelaxation can be induced in two ways: endothelium dependent (stimulated by acetylcholine) and endothelium inde pendent (experimentally inducible by sodium nitroprusside). Only the first one is affected by oxidative stress through hydrogen per oxide or hypochlorite (for two recent publications, see Radovits et al., 2007a,b) and PARP inhibition especially rescued this endo thelium dependent vasorelaxation [see also (Pacher et al., 2002b)].

In summary, PARP inhibition probably does not reduce initial damage, but diminishes the ongoing formation of reactive com pounds like $\mathrm{NO}^{*}$ and subsequently peroxynitrite. This preserves en ergy metabolites and blocks the translocation of AIF from the mitochondria into the nucleus. Thus, necrosis is reduced as well as overall cell death. Inflammation (neutrophil activation) is sup pressed and the resulting morphological changes like hypertrophy are diminished. These all together leads to an improved function ality of the heart and a reduction in infarct size [for reviews, see (Csiszar et al., 2005; Pacher and Szabo, 2007; Szabo, 2005)].

\subsection{Transplantation}

As most of the experiments show beneficial effects by treating the hearts with PARP inhibitors before or during ischemia, an obvi ous field of application would be transplantation medicine. Many publications cover parts of this aspect. Administering PJ34 during rat heart transplantation improved organ performance (Szabo et al., 2002b). After $1 \mathrm{~h}$ of hypothermic preservation, the inhibitor was applied and kept constant during reperfusion for $1 \mathrm{~h}$ up to $24 \mathrm{~h}$. Again, PARP activity was prevented and energy content pre served. Also, the elevation of P selectin and ICAM 1 expression de tected in vehicle controls was diminished. In line with this, another transplantation study pre treated donor and recipient rats with the PARP inhibitor $3 \mathrm{AB}$, with the structurally similar, but non func tional molecule 3 aminobenzoic acid (3ABA), or with vehicle only (Fiorillo et al., 2003). As a result, controls and 3ABA treated animals showed clear signs of oxidative stress like elevated lipid oxidation, protein carbonyls and DNA damage. PARP activity was increased and $\mathrm{NAD}^{+}$as well as ATP levels dropped. Heart damage markers were increased and the tissue was partially necrotic with a low abundance of apoptosis. $3 \mathrm{AB}$ treated animals showed less oxida tive stress and heart damage makers. Likewise, PAR formation was impaired and the energy metabolite levels were preserved. Necrosis was not the prevalent death pathway as in transplanted controls but apoptosis, and the overall cell death rate was dimin ished. Also, cardiopulmonary bypass leads to induction of apopto sis in cardiac tissue. Adding $3 \mathrm{AB}$ to the cardioplegic solution in cardiopulmonary bypassed hearts of rabbits diminished cardiomy ocyte apoptosis and reduced the expression of pro inflammatory cytokines (Yeh et al., 2006a).

\section{PARP activity and survival signaling}

Is the suppression of inflammation and preserving energy the only way by which PARP inhibition protects tissues from damage?

In 2003, Veres and colleagues provided evidence that PARP inhi bition in mice before and one hour after LPS application reduced TNF $\alpha$ expression and improved survival of the animals, and this was dependent on the induction of the Akt/PKB pathway (Veres et al., 2003). One year later, the same group showed that PARP inhi bition blunted the induction of MAP kinases (p38 and ERK) and downstream targets NFKB and AP 1 after LPS treatment (Veres et al., 2004). In 2005, Tapodi and colleagues could show that cyto 
protectivity of PARP inhibition strictly depended on the Akt kinase pathway. Inhibition of the activators of Akt, which belong to the phosphoinositol 3 kinase superfamily, by i.e., wortmannin totally abolished the beneficial effects of inhibiting poly(ADP ribose) polymerases in cells (Tapodi et al., 2005). This could be confirmed also in animal models, where isolated beating rat hearts subjected to ischemia reperfusion showed after PARP inhibition improve ments like reduced oxidative stress and infarct size. Phosphoryla tion of the pro survival kinase Akt was increased and addition of wortmannin reduced Akt phosphorylation and also the protective effect of PARP inhibition (Gao et al., 2007; Kovacs et al., 2006).

Of note is the fact that in a human patient study, myocardial infarction led to an increase in the nitrotyrosine levels and PAR for mation in circulating leukocytes (Toth Zsamboki et al., 2006). Most likely, this was dependent on the production of pro inflammatory cytokines in the infarcted region, stimulating and attracting im mune cells. Thus, elevated poly(ADP ribosyl)ation may serve as an easily detectable marker for infarctions in future.

\section{Summary}

Poly(ADP ribose) polymerases cover many aspects in cellular regulatory networks, most prominently genomic stability. Thus, a functional poly(ADP ribosyl)ation system is most important for cellular survival. But too much PARP activity after DNA damage can lead to cell death due to energy failure or by triggering cas pase independent cell death via AIF. These phenomena can be eas ily investigated in cell culture, but in organs and organisms, another layer of complexity arises from PARPs, i.e., the regulation of inflammation, with the amplifying impact on resulting patholo gies and the subsequent induction of cytokines and cell migration between different tissues. Here, the dependency of the master reg ulator of immune reactions, NFKB, on PARP 1 for its transcriptional activity is decisive. Although some in vitro data report that PARP 1 protein and not the enzymatic activity is necessary for NFKB dependent transcription (Hassa et al., 2003, 2001), this is not sup ported by in vivo experiments, where pharmacological PARP inhi bition is clearly effective in suppressing inflammation. Therefore, maybe additional factors await discovery that link PAR and NFKB functionality in vivo. The connection between severe DNA damage with resulting necrotic cell death and inflammation leads to a vi cious circle (see Fig. 1): ischemia leads to hypoxia and necrosis in affected tissues. Released cellular contents include ROS and pro inflammatory molecules. ROS damage the DNA of surrounding cells, leading to PARP activation. PAR production consumes sub stantial amounts of $\mathrm{NAD}^{+}$, resulting in energy failure and necrosis, amplifying this first branch. Pro inflammatory molecules attract immune cells, which release ROS and lytic molecules in their envi ronment, leading to more cell death in the second branch. Also, PARP activity triggers the transcriptional activity of NFKB, resulting in expression of iNOS and more cytokines. This enhances both branches, resulting in a doubled vicious circle.

The available literature suggests that inhibiting poly(ADP ribo syl)ation bears a great potential for clinical applications. Treatment of chronic diseases like diabetes or Crohn's disease might be im proved by administration of PARP inhibitors. But it will be neces sary to determine the shortest time period of treatment that still leads to long term improvements, because constant suppression of this important enzymatic pathway regulating genome stability could have deleterious side effects. Short term application on the other hand can be very beneficial, for example, in sepsis where PARP inhibition can be used to block the overstimulation of the im mune system. Also in the context of transplantation medicine po tent PARP inhibitors might be useful to suppress temporarily inflammation and improve cell survival and organ functionality if

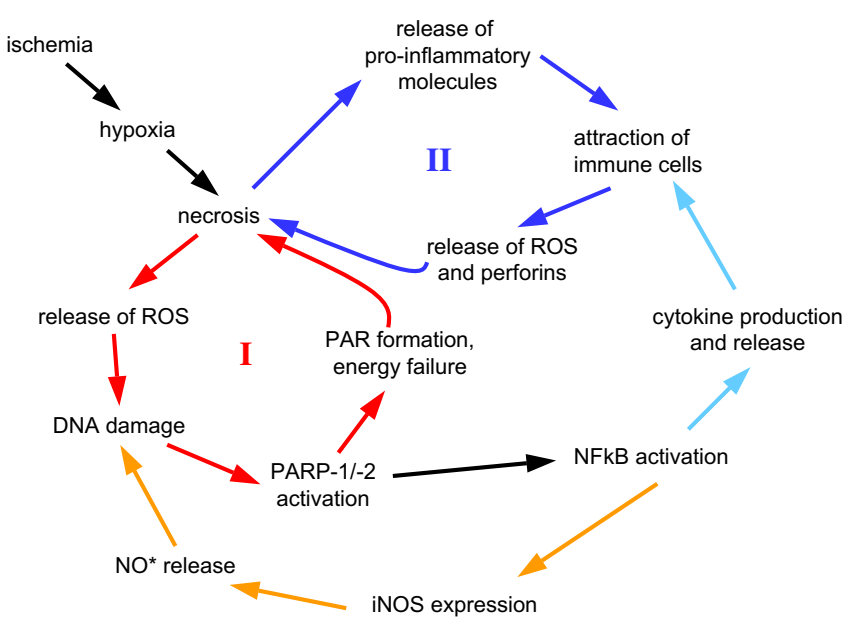

Fig. 1. Ischemia leads to hypoxic conditions in tissues, followed by reperfusion. Subsequent necrosis leads to cell rupture and release of cellular contents into the surrounding tissue. ROS are able to damage neighboring cells including their DNA, thus triggering the activity of repair-PARPs (i.e., PARP-1 and 2). If the damage load is high, substantial amounts of $\mathrm{NAD}^{+}$are consumed and cells die from energy failure, amplifying the necrotic process (vicious circle I, red arrows). Also, released proinflammatory molecules trigger attraction of immune cells. These in turn release of ROS or lytic proteins like perforins, which also amplify the necrotic process (vicious circle II, blue arrows). Furthermore, activated PARP-1 stimulates the transcriptional activity of NFKB. Expression of iNOS leads to NO radical production and release, further increasing DNA damage and PARP activation (orange arrows). Expression of cytokines recruits more immune cells and the release of more cell damaging molecules, amplifying the second vicious circle (light blue arrows). (For interpretation of the references to color in this figure legend, the reader is referred to the web version of this paper.)

administered during surgical procedure. But maybe these com pounds can also be used for treatment of acute ischemic insults, preserving energy metabolites, and suppress activation of immune cells. Promoting cell survival and switching from necrosis to apop tosis in the population of dying cells would keep inflammation in check, diminishing the affected infarct area with beneficial impact for the patient. To achieve this goal, more experiments have to be done using controlled time courses in order to define, at which point during or after ischemia PARP inhibitors are still effective. Furthermore, it has to be taken into account that different tissues may react differently to PARP inhibition, as the results described in the liver injury section suggest. Hopefully, a better understand ing of where and when suppression of PARP activity is improving tissue functionality will start a new era of intervention for ische mia reperfusion injury.

\section{Acknowledgment}

The author thanks Prof. Alexander Bürkle for his constant sup port and for critical reading of the manuscript.

\section{References}

Abdelkarim, G.E., Gertz, K., Harms, C., Katchanov, J., Dirnagl, U., Szabo, C., Endres, M. 2001. Protective effects of PJ34, a novel, potent inhibitor of poly(ADP-ribose) polymerase (PARP) in in vitro and in vivo models of stroke. Int. J. Mol. Med. 7, $255-260$.

Ame, J.C., Spenlehauer, C., de Murcia, G., 2004. The PARP superfamily. Bioessays 26, 882-893.

Beneke, S., Burkle, A., 2007. Poly(ADP-ribosyl)ation in mammalian ageing. Nucleic Acids Res. 35, 7456-7465.

Berger, N.A., Sims, J.L., Catino, D.M., Berger, S.J., 1983. Poly(ADP-ribose) polymerase mediates the suicide response to massive DNA damage: studies in normal and DNA-repair defective cells. Princess Takamatsu Symp. 13, 219-226.

Bonicalzi, M.E., Haince, J.F., Droit, A., Poirier, G.G., 2005. Regulation of poly(ADPribose) metabolism by poly(ADP-ribose) glycohydrolase: where and when? Cell. Mol. Life Sci. 62, 739-750. 
Boulares, A.H., Zoltoski, A.J., Sherif, Z.A., Jolly, P., Massaro, D., Smulson, M.E., 2003. Gene knockout or pharmacological inhibition of poly(ADP-ribose) polymerase-1 prevents lung inflammation in a murine model of asthma. Am. J. Respir. Cell Mol. Biol. 28, 322-329.

Boulos, M., Astiz, M.E., Barua, R.S., Osman, M., 2003. Impaired mitochondrial function induced by serum from septic shock patients is attenuated by inhibition of nitric oxide synthase and poly(ADP-ribose) synthase. Crit. Care Med. 31, 353-358.

Bowes, J., Ruetten, H., Martorana, P.A., Stockhausen, H., Thiemermann, C., 1998 Reduction of myocardial reperfusion injury by an inhibitor of poly (ADP-ribose) synthetase in the pig. Eur. J. Pharmacol. 359, 143-150.

Bowes, J., Thiemermann, C., 1998. Effects of inhibitors of the activity of poly (ADPribose) synthetase on the liver injury caused by ischaemia-reperfusion: a comparison with radical scavengers. Br. J. Pharmacol. 124, 1254-1260.

Bürkle, A., 2001. Poly(ADP-ribosyl)ation, a DNA damage-driven protein modification and regulator of genomic instability. Cancer Lett. 163, 1-5.

Chambon, P., Weill, J.D., Mandel, P., 1963. Nicotinamide mononucleotide activation of new DNA-dependent polyadenylic acid synthesizing nuclear enzyme. Biochem. Biophys. Res. Commun. 11, 39-43.

Chang, P., Coughlin, M., Mitchison, T.J., 2005. Tankyrase-1 polymerization of poly(ADP-ribose) is required for spindle structure and function. Nat. Cell Biol. 7, 1133-1139.

Chen, C.F., Wang, D., Lin, H.I., Leu, F.J., Shen, C.Y., Chou, C.C., 2007. Ischemia/ reperfusion of the liver induces heart injury in rats. Transpl. Proc. 39, 855-857.

Chi, N.W., Lodish, H.F., 2000. Tankyrase is a golgi-associated mitogen-activated protein kinase substrate that interacts with IRAP in GLUT4 vesicles. J. Biol. Chem. 275, 38437-38444.

Chiarugi, A., 2005. Poly(ADP-ribosyl)ation and stroke. Pharmacol. Res. 52, 15-24.

Chiarugi, A., Moskowitz, M.A., 2003. Poly(ADP-ribose) polymerase-1 activity promotes NF-kappaB-driven transcription and microglial activation: implication for neurodegenerative disorders. J. Neurochem. 85, 306-317.

Cover, C., Fickert, P., Knight, T.R., Fuchsbichler, A., Farhood, A., Trauner, M., Jaeschke, H., 2005. Pathophysiological role of poly(ADP-ribose) polymerase (PARP) activation during acetaminophen-induced liver cell necrosis in mice. Toxicol. Sci. 84, 201-208.

Cregan, S.P., Dawson, V.L., Slack, R.S., 2004. Role of AIF in caspase-dependent and caspase-independent cell death. Oncogene 23, 2785-2796.

Csiszar, A., Pacher, P., Kaley, G., Ungvari, Z., 2005. Role of oxidative and nitrosative stress, longevity genes and poly(ADP-ribose) polymerase in cardiovascular dysfunction associated with aging. Curr. Vasc. Pharmacol. 3, 285-291.

Cuzzocrea, S., Wang, Z.Q., 2005. Role of poly(ADP-ribose) glycohydrolase (PARG) in shock, ischemia and reperfusion. Pharmacol. Res. 52, 100-108.

Cuzzocrea, S., Zingarelli, B., Costantino, G., Szabo, A., Salzman, A.L., Caputi, A.P. Szabo, C., 1997a. Beneficial effects of 3-aminobenzamide, an inhibitor of poly (ADP-ribose) synthetase in a rat model of splanchnic artery occlusion and reperfusion. Br. J. Pharmacol. 121, 1065-1074.

Cuzzocrea, S., Zingarelli, B., O'Connor, M., Salzman, A.L., Caputi, A.P., Szabo, C., 1997b. Role of peroxynitrite and activation of poly (ADP-ribose) synthase in the vascular failure induced by zymosan-activated plasma. Br. J. Pharmacol. 122, 493-503.

Dantzer, F., Giraud-Panis, M.J., Jaco, I., Ame, J.C., Schultz, I., Blasco, M., Koering, C.E., Gilson, E., Menissier-de Murcia, J., de Murcia, G., Schreiber, V., 2004. Functional interaction between poly(ADP-Ribose) polymerase 2 (PARP-2) and TRF2: PARP activity negatively regulates TRF2. Mol. Cell. Biol. 24, 15951607.

de Murcia, J.M., Niedergang, C., Trucco, C., Ricoul, M., Dutrillaux, B., Mark, M., Oliver, F.J., Masson, M., Dierich, A., LeMeur, M., Walztinger, C., Chambon, P., de Murcia, G., 1997. Requirement of poly(ADP-ribose) polymerase in recovery from DNA damage in mice and in cells. Proc. Natl. Acad. Sci. USA 94, 7303-7307.

Di Paola, R., Mazzon, E., Xu, W., Genovese, T., Ferrraris, D., Muia, C., Crisafulli, C., Zhang, J., Cuzzocrea, S., 2005. Treatment with PARP-1 inhibitors, GPI 15427 or GPI 16539, ameliorates intestinal damage in rat models of colitis and shock. Eur. J. Pharmacol. 527, 163-171.

Eliasson, M.J., Sampei, K., Mandir, A.S., Hurn, P.D., Traystman, R.J., Bao, J., Pieper, A. Wang, Z.Q., Dawson, T.M., Snyder, S.H., Dawson, V.L., 1997. Poly(ADP-ribose) polymerase gene disruption renders mice resistant to cerebral ischemia. Nat. Med. 3, 1089-1095

Endres, M., Scott, G., Namura, S., Salzman, A.L., Huang, P.L., Moskowitz, M.A., Szabo, C., 1998a. Role of peroxynitrite and neuronal nitric oxide synthase in the activation of poly(ADP-ribose) synthetase in a murine model of cerebral ischemia-reperfusion. Neurosci. Lett. 248, 41-44.

Endres, M., Scott, G.S., Salzman, A.L., Kun, E., Moskowitz, M.A., Szabo, C., 1998b. Protective effects of 5-iodo-6-amino-1,2-benzopyrone, an inhibitor of poly(ADP-ribose) synthetase against peroxynitrite-induced glial damage and stroke development. Eur. J. Pharmacol. 351, 377-382.

Endres, M., Wang, Z.Q., Namura, S., Waeber, C., Moskowitz, M.A., 1997. Ischemic brain injury is mediated by the activation of poly(ADP-ribose)polymerase. J. Cereb. Blood Flow Metab. 17, 1143-1151.

Faro, R., Toyoda, Y., McCully, J.D., Jagtap, P., Szabo, E., Virag, L., Bianchi, C., Levitsky, S., Szabo, C., Sellke, F.W., 2002. Myocardial protection by PJ34, a novel potent poly (ADP-ribose) synthetase inhibitor. Ann. Thorac. Surg. 73, 575-581.

Fiorillo, C., Ponziani, V., Giannini, L., Cecchi, C., Celli, A., Nassi, N., Lanzilao, L. Caporale, R., Nassi, P., 2006. Protective effects of the PARP-1 inhibitor PJ34 in hypoxic-reoxygenated cardiomyoblasts. Cell. Mol. Life Sci. 63, 3061-3071.

Fiorillo, C., Ponziani, V., Giannini, L., Cecchi, C., Celli, A., Nediani, C., Perna, A.M., Liguori, P., Nassi, N., Formigli, L., Tani, A., Nassi, P., 2003. Beneficial effects of poly (ADP-ribose) polymerase inhibition against the reperfusion injury in heart transplantation. Free Radic. Res. 37, 331-339.

Fousteri, M., Mullenders, L.H., 2008. Transcription-coupled nucleotide excision repair in mammalian cells: molecular mechanisms and biological effects. Cell Res. 18, 73-84.

Gao, L., Kwan, J.C., Macdonald, P.S., Yang, L., Preiss, T., Hicks, M., 2007. Improved poststorage cardiac function by poly (ADP-ribose) polymerase inhibition: role of phosphatidylinositol 3-kinase Akt pathway. Transplantation 84, 380-386.

Garcia, M.J., Benitez, J., 2008. The Fanconi anaemia/BRCA pathway and cancer susceptibility. Searching for new therapeutic targets. Clin. Transl. Oncol. 10, 7884.

Genovese, T., Mazzon, E., Di Paola, R., Muia, C., Threadgill, M.D., Caputi, A.P. Thiemermann, C., Cuzzocrea, S., 2005. Inhibitors of poly(ADP-ribose) polymerase modulate signal transduction pathways and the development of bleomycin-induced lung injury. J. Pharmacol. Exp. Ther. 313, 529-538.

Gero, D., Szabo, C., 2006. Role of the peroxynitrite-poly (ADP-ribose) polymerase pathway in the pathogenesis of liver injury. Curr. Pharm. Des. 12, 2903-2910.

Gilad, E., Zingarelli, B., Salzman, A.L., Szabo, C., 1997. Protection by inhibition of poly (ADP-ribose) synthetase against oxidant injury in cardiac myoblasts In vitro. J. Mol. Cell. Cardiol. 29, 2585-2597.

Goldfarb, R.D., Marton, A., Szabo, E., Virag, L., Salzman, A.L., Glock, D., Akhter, I., McCarthy, R., Parrillo, J.E., Szabo, C., 2002. Protective effect of a novel, potent inhibitor of poly(adenosine $5^{\prime}$-diphosphate-ribose) synthetase in a porcine model of severe bacterial sepsis. Crit. Care Med. 30, 974-980.

Haddad, M., Rhinn, H., Bloquel, C., Coqueran, B., Szabo, C., Plotkine, M., Scherman, D. Margaill, I., 2006. Anti-inflammatory effects of PJ34, a poly(ADP-ribose) polymerase inhibitor, in transient focal cerebral ischemia in mice. Br. J. Pharmacol. 149, 23-30.

Hamby, A.M., Suh, S.W., Kauppinen, T.M., Swanson, R.A., 2007. Use of a poly(ADPribose) polymerase inhibitor to suppress inflammation and neuronal death after cerebral ischemia-reperfusion. Stroke 38, 632-636.

Hartge, M.M., Unger, T., Kintscher, U., 2007. The endothelium and vascular inflammation in diabetes. Diab. Vasc. Dis. Res. 4, 84-88.

Hasko, G., Mabley, J.G., Nemeth, Z.H., Pacher, P., Deitch, E.A., Szabo, C., 2002 Poly(ADP-ribose) polymerase is a regulator of chemokine production: relevance for the pathogenesis of shock and inflammation. Mol. Med. 8, 283-289.

Hassa, P.O., Buerki, C., Lombardi, C., Imhof, R., Hottiger, M.O., 2003. Transcriptional coactivation of nuclear factor-kappaB-dependent gene expression by $\mathrm{p} 300$ is regulated by poly(ADP)-ribose polymerase-1. J. Biol. Chem. 278, 45145-45153.

Hassa, P.O. Covic, M. Hasan, S. Imhof, R. Hottiger, M.O., 2001. The enzymatic and DNA binding activity of PARP-1 are not required for NF-kappa B coactivator function. J. Biol. Chem. 276, 45588-45597.

Hassa, P.O., Hottiger, M.O., 2002. The functional role of poly(ADP-ribose)polymerase 1 as novel coactivator of NF-kappaB in inflammatory disorders. Cell. Mol. Life Sci. 59, 1534-1553.

Hauschildt, S., Scheipers, P., Bessler, W., Schwarz, K., Ullmer, A., Flad, H.D., Heine, H., 1997. Role of ADP-ribosylation in activated monocytes/macrophages. Adv. Exp. Med. Biol. 419, 249-252.

Hauschildt, S., Scheipers, P., Bessler, W.G., Mulsch, A., 1992. Induction of nitric oxide synthase in $\mathrm{L} 929$ cells by tumour-necrosis factor alpha is prevented by inhibitors of poly(ADP-ribose) polymerase. Biochem. J. (Pt. 1), 255-260.

Heller, B., Wang, Z.Q., Wagner, E.F., Radons, J., Burkle, A., Fehsel, K., Burkart, V., Kolb H., 1995. Inactivation of the poly(ADP-ribose) polymerase gene affects oxygen radical and nitric oxide toxicity in islet cells. J. Biol. Chem. 270, 11176-11180.

Hermans, M.P., 2007. Diabetes and the endothelium. Acta Clin. Belg. 62, 97-101.

Hudak, B.B., Tufariello, J., Sokolowski, J., Maloney, C., Holm, B.A., 1995. Inhibition of poly(ADP-ribose) polymerase preserves surfactant synthesis after hydrogen peroxide exposure. Am. J. Physiol. 269, L59-L64.

Ilnytska, O., Lyzogubov, V.V., Stevens, M.J., Drel, V.R., Mashtalir, N., Pacher, P., Yorek, M.A., Obrosova, I.G., 2006. Poly(ADP-ribose) polymerase inhibition alleviates experimental diabetic sensory neuropathy. Diabetes 55, 1686-1694.

Inada, C., Yamada, K., Takane, N., Nonaka, K., 1995. Poly(ADP-ribose) synthesis induced by nitric oxide in a mouse beta-cell line. Life Sci. 56, 1467-1474.

Ivanyi, Z., Hauser, B., Pittner, A., Asfar, P., Vassilev, D., Nalos, M., Altherr, J., Bruckner, U.B., Szabo, C., Radermacher, P., Froba, G., 2003. Systemic and hepatosplanchnic hemodynamic and metabolic effects of the PARP inhibitor PJ34 during hyperdynamic porcine endotoxemia. Shock 19, 415-421.

Jagtap, P., Soriano, F.G., Virag, L., Liaudet, L., Mabley, J., Szabo, E., Hasko, G., Marton, A., Lorigados, C.B., Gallyas Jr., F., Sumegi, B., Hoyt, D.G., Baloglu, E., VanDuzer, J., Salzman, A.L., Southan, G.J., Szabo, C., 2002. Novel phenanthridinone inhibitors of poly (adenosine 5'-diphosphate-ribose) synthetase: potent cytoprotective and antishock agents. Crit. Care Med. 30, 1071-1082.

Jijon, H.B., Churchill, T., Malfair, D., Wessler, A., Jewell, L.D., Parsons, H.G., Madsen, K.L., 2000. Inhibition of poly(ADP-ribose) polymerase attenuates inflammation in a model of chronic colitis. Am. J. Physiol. Gastrointest. Liver Physiol. 279, G641-G651.

Kallmann, B., Burkart, V., Kroncke, K.D., Kolb-Bachofen, V., Kolb, H., 1992. Toxicity of chemically generated nitric oxide towards pancreatic islet cells can be prevented by nicotinamide. Life Sci. 51, 671-678.

Kao, S.J., Liu, D.D., Su, C.F., Chen, H.I., 2007. Niacinamide abrogates the organ dysfunction and acute lung injury caused by endotoxin. J. Cardiovasc Pharmacol. 50, 333-342.

Khandoga, A., Biberthaler, P., Enders, G., Krombach, F., $2004 . \quad 5-$ Aminoisoquinolinone, a novel inhibitor of poly(adenosine diphosphate-ribose) polymerase, reduces microvascular liver injury but not mortality rate after hepatic ischemia-reperfusion. Crit. Care Med. 32, 472-477. 
Kiefmann, R., Heckel, K., Doerger, M., Schenkat, S., Kupatt, C., Stoeckelhuber, M. Wesierska-Gadek, J., Goetz, A.E., 2004. Role of PARP on iNOS pathway during endotoxin-induced acute lung injury. Inten. Care Med. 30, 1421-1431.

Koksel, O., Yildirim, C., Cinel, L., Tamer, L., Ozdulger, A., Basturk, M., Degirmenci, U. Kanik, A., Cinel, I., 2005. Inhibition of poly(ADP-ribose) polymerase attenuates lung tissue damage after hind limb ischemia-reperfusion in rats. Pharmacol. Res. 51, 453-462.

Kovacs, K., Toth, A., Deres, P., Kalai, T., Hideg, K., Gallyas Jr., F., Sumegi, B., 2006. Critical role of PI3-kinase/Akt activation in the PARP inhibitor induced heart function recovery during ischemia-reperfusion. Biochem. Pharmacol. 71, 441452.

Lavin, M.F., 2007. ATM and the Mre11 complex combine to recognize and signal DNA double-strand breaks. Oncogene 26, 7749-7758.

Lenzser, G., Kis, B., Snipes, J.A., Gaspar, T., Sandor, P., Komjati, K., Szabo, C., Busija D.W., 2007. Contribution of poly(ADP-ribose) polymerase to postischemic blood-brain barrier damage in rats. J. Cereb. Blood Flow Metab. 27, 1318-1326.

Liaudet, L., Pacher, P., Mabley, J.G., Virag, L., Soriano, F.G., Hasko, G., Szabo, C., 2002. Activation of poly(ADP-Ribose) polymerase-1 is a central mechanism of lipopolysaccharide-induced acute lung inflammation. Am. J. Respir. Crit. Care Med. 165, 372-377.

Mabley, J.G., Suarez-Pinzon, W.L., Hasko, G., Salzman, A.L., Rabinovitch, A., Kun, E. Szabo, C., 2001. Inhibition of poly (ADP-ribose) synthetase by gene disruption or inhibition with 5-iodo-6-amino-1,2-benzopyrone protects mice from multiplelow-dose-streptozotocin-induced diabetes. Br. J. Pharmacol. 133, 909-919.

Mazzon, E., Dugo, L., Li, J.H., Di Paola, R., Genovese, T., Caputi, A.P., Zhang, J., Cuzzocrea, S., 2002. GPI 6150, a PARP inhibitor, reduces the colon injury caused by dinitrobenzene sulfonic acid in the rat. Biochem. Pharmacol. 64, 327-337.

Menissier de Murcia, J., Ricoul, M., Tartier, L., Niedergang, C., Huber, A., Dantzer, F. Schreiber, V., Ame, J.C., Dierich, A., LeMeur, M., Sabatier, L., Chambon, P., de Murcia, G., 2003. Functional interaction between PARP-1 and PARP-2 in chromosome stability and embryonic development in mouse. EMBO J. 22, 2255-2263.

Meyer-Ficca, M.L., Meyer, R.G., Coyle, D.L., Jacobson, E.L., Jacobson, M.K., 2004 Human poly(ADP-ribose) glycohydrolase is expressed in alternative splice variants yielding isoforms that localize to different cell compartments. Exp. Cell Res. 297, 521-532.

Murakami, K., Enkhbaatar, P., Shimoda, K., Cox, R.A., Burke, A.S., Hawkins, H.K., Traber, L.D., Schmalstieg, F.C., Salzman, A.L., Mabley, J.G., Komjati, K., Pacher, P., Zsengeller, Z., Szabo, C., Traber, D.L., 2004. Inhibition of poly (ADP-ribose) polymerase attenuates acute lung injury in an ovine model of sepsis. Shock 21 , 126-133.

Naura, A.S., Hans, C.P., Zerfaoui, M., You, D., Cormier, S.A., Oumouna, M., Boulares A.H., 2008. Post-allergen challenge inhibition of poly(ADP-ribose) polymerase harbors therapeutic potential for treatment of allergic airway inflammation. Clin. Exp. Allergy. 38, 839-846.

Nicolls, M.R., Haskins, K., Flores, S.C., 2007. Oxidant stress, immune dysregulation, and vascular function in type I diabetes. Antioxid. Redox Signal. 9, 879-889.

O'Connor, M.S., Safari, A., Liu, D., Qin, J., Songyang, Z., 2004. The human Rap1 protein complex and modulation of telomere length. J. Biol. Chem. 279, 28585-28591.

Oliver, F.J., Menissier-de Murcia, J., Nacci, C., Decker, P., Andriantsitohaina, R Muller, S., de la Rubia, G., Stoclet, J.C., de Murcia, G., 1999. Resistance to endotoxic shock as a consequence of defective NF-kappaB activation in poly (ADP-ribose) polymerase-1 deficient mice. EMBO J. 18, 4446-4454.

Ollikainen, T, Puhakka, A, Kahlos, K., Linnainmaa, K. Kinnula, V.L., 2000. Modulation of cell and DNA damage by poly(ADP)ribose polymerase in lung cells exposed to $\mathrm{H}(2) \mathrm{O}(2)$ or asbestos fibres. Mutat. Res. 470, 77-84.

Oumouna, M., Datta, R., Oumouna-Benachour, K., Suzuki, Y., Hans, C., Matthews, K. Fallon, K., Boulares, H., 2006. Poly(ADP-ribose) polymerase-1 inhibition prevents eosinophil recruitment by modulating Th2 cytokines in a murine model of allergic airway inflammation: a potential specific effect on IL-5. J Immunol. 177, 6489-6496.

Pacher, P., Liaudet, L., Mabley, J., Komjati, K., Szabo, C., 2002a. Pharmacologic inhibition of poly(adenosine diphosphate-ribose) polymerase may represent novel therapeutic approach in chronic heart failure. J. Am. Coll. Cardiol. 40, 1006-1016.

Pacher, P., Liaudet, L., Soriano, F.G., Mabley, J.G., Szabo, E., Szabo, C., 2002b. The role of poly(ADP-ribose) polymerase activation in the development of myocardia and endothelial dysfunction in diabetes. Diabetes 51, 514-521.

Pacher, P., Szabo, C., 2005. Role of poly(ADP-ribose) polymerase-1 activation in the pathogenesis of diabetic complications: endothelial dysfunction, as a common underlying theme. Antioxid. Redox Signal. 7, 1568-1580.

Pacher, P., Szabo, C., 2007. Role of poly(ADP-ribose) polymerase 1 (PARP-1) in cardiovascular diseases: the therapeutic potential of PARP inhibitors. Cardiovasc. Drug Rev. 25, 235-260.

Pieper, A.A., Brat, D.J., Krug, D.K., Watkins, C.C., Gupta, A., Blackshaw, S., Verma, A Wang, Z.Q., Snyder, S.H., 1999. Poly(ADP-ribose) polymerase-deficient mice are protected from streptozotocin-induced diabetes. Proc. Natl. Acad. Sci. USA 96, 3059-3064.

Pieper, A.A., Walles, T., Wei, G., Clements, E.E., Verma, A., Snyder, S.H., Zweier, J.L., 2000. Myocardial postischemic injury is reduced by polyADPribose polymerase1 gene disruption. Mol. Med. 6, 271-282.

Popoff, I. Jijon, H., Monia, B., Tavernini, M., Ma, M., McKay, R, Madsen, K., 2002. Antisense oligonucleotides to poly(ADP-ribose) polymerase-2 ameliorate colitis in interleukin-10-deficient mice. J. Pharmacol. Exp. Ther. 303, 1145-1154.

Radons, J., Heller, B., Burkle, A., Hartmann, B., Rodriguez, M.L., Kroncke, K.D., Burkart, V., Kolb, H., 1994. Nitric oxide toxicity in islet cells involves poly(ADP-ribose) polymerase activation and concomitant NAD+ depletion. Biochem. Biophys. Res. Commun. 199, 1270-1277.

Radovits, T., Lin, L.N., Zotkina, J., Gero, D., Szabo, C., Karck, M., Szabo, G., 2007a. Poly(ADP-ribose) polymerase inhibition improves endothelial dysfunction induced by reactive oxidant hydrogen peroxide in vitro. Eur. J. Pharmacol. 564, 158-166.

Radovits, T., Zotkina, J., Lin, L.N., Bomicke, T., Arif, R., Gero, D., Horvath, E.M., Karck, M., Szabo, C., Szabo, G., 2007b. Poly(ADP-Ribose) polymerase inhibition improves endothelial dysfunction induced by hypochlorite. Exp. Biol. Med. (Maywood) 232, 1204-1212.

Reusch, J.E., Draznin, B.B., 2007. Atherosclerosis in diabetes and insulin resistance. Diab. Obes. Metab. 9, 455-463.

Rustgi, A.K., 2007. The genetics of hereditary colon cancer. Genes Dev. 21, 25252538 .

Schreiber, V., Ame, J.C., Dolle, P., Schultz, I., Rinaldi, B., Fraulob, V., Menissier-de Murcia, J., de Murcia, G., 2002. Poly(ADP-ribose) polymerase-2 (PARP-2) is required for efficient base excision DNA repair in association with PARP-1 and XRCC1. J. Biol. Chem. 277, 23028-23036.

Scovassi, A.I., 2004. Mitochondrial poly(ADP-ribosylation): from old data to new perspectives. FASEB J. 18, 1487-1488.

Shieh, W.M., Ame, J.C., Wilson, M.V., Wang, Z.Q., Koh, D.W., Jacobson, M.K., Jacobson, E.L., 1998. Poly(ADP-ribose) polymerase null mouse cells synthesize ADP-ribose polymers. J. Biol. Chem. 273, 30069-30072.

Shuck, S.C., Short, E.A., Turchi, J.J., 2008. Eukaryotic nucleotide excision repair: from understanding mechanisms to influencing biology. Cell Res. 18, 64-72.

Sims, J.L., Berger, S.J., Berger, N.A., 1983. Poly(ADP-ribose) Polymerase inhibitors preserve nicotinamide adenine dinucleotide and adenosine $5^{\prime}$-triphosphate pools in DNA-damaged cells: mechanism of stimulation of unscheduled DNA synthesis. Biochemistry 22, 5188-5194.

Smith, S., Giriat, I., Schmitt, A., de Lange, T., 1998. Tankyrase, a poly(ADP-ribose) polymerase at human telomeres. Science 282, 1484-1487.

Stehr, A., Ploner, F., Tugtekin, I., Matejovic, M., Theisen, M., Zulke, C., Georgieff, M., Radermacher, P., Jauch, K.W., 2003. Effect of combining nicotinamide as a PARSinhibitor with selective iNOS blockade during porcine endotoxemia. Inten. Care Med. 29, 995-1002.

Su, C.F., Liu, D.D., Kao, S.J., Chen, H.I., 2007. Nicotinamide abrogates acute lung injury caused by ischaemia/reperfusion. Eur. Respir. J. 30, 199-204.

Suzuki, Y., Masini, E., Mazzocca, C., Cuzzocrea, S., Ciampa, A., Suzuki, H., Bani, D., 2004. Inhibition of poly(ADP-ribose) polymerase prevents allergen-induced asthma-like reaction in sensitized Guinea pigs. J. Pharmacol. Exp. Ther. 311, 1241-1248.

Szabo, C., 2005. Cardioprotective effects of poly(ADP-ribose) polymerase inhibition. Pharmacol. Res. 52, 34-43.

Szabo, C., 2006. Poly(ADP-ribose) polymerase activation by reactive nitrogen species - relevance for the pathogenesis of inflammation. Nitric Oxide 14, 169-179.

Szabo, C., 2007. Poly (ADP-ribose) polymerase activation and circulatory shock Novartis Found. Symp. 280, 92-103 (discussion 103-107, 160-164).

Szabo, C., Lim, L.H., Cuzzocrea, S., Getting, S.J., Zingarelli, B., Flower, R.J., Salzman, A.L., Perretti, M., 1997. Inhibition of poly (ADP-ribose) synthetase attenuates neutrophil recruitment and exerts antiinflammatory effects. J. Exp. Med. 186, 1041-1049.

Szabo, C., Zanchi, A., Komjati, K., Pacher, P., Krolewski, A.S., Quist, W.C., LoGerfo, F.W., Horton, E.S., Veves, A., 2002a. Poly(ADP-Ribose) polymerase is activated in subjects at risk of developing type 2 diabetes and is associated with impaired vascular reactivity. Circulation 106, 2680-2686.

Szabo, C., Zingarelli, B., Salzman, A.L., 1996. Role of poly-ADP ribosyltransferase activation in the vascular contractile and energetic failure elicited by exogenous and endogenous nitric oxide and peroxynitrite. Circ. Res. 78, 1051-1063.

Szabo, G., Bahrle, S., Stumpf, N., Sonnenberg, K., Szabo, E.E., Pacher, P., Csont, T., Schulz, R., Dengler, T.J., Liaudet, L., Jagtap, P.G., Southan, G.J., Vahl, C.F., Hagl, S., Szabo, C., 2002b. Poly(ADP-Ribose) polymerase inhibition reduces reperfusion injury after heart transplantation. Circ. Res. 90, 100-106.

Szijarto, A., Batmunkh, E., Hahn, O., Mihaly, Z., Kreiss, A., Kiss, A., Lotz, G., Schaff, Z., Vali, L., Blazovics, A., Gero, D., Szabo, C., Kupcsulik, P., 2007. Effect of PJ-34 PARPinhibitor on rat liver microcirculation and antioxidant status. J. Surg. Res. 142, 72-80.

Takahashi, K., Greenberg, J.H., Jackson, P., Maclin, K., Zhang, J., 1997. Neuroprotective effects of inhibiting poly(ADP-ribose) synthetase on focal cerebral ischemia in rats. J. Cereb. Blood Flow Metab. 17, 1137-1142.

Takahashi, K., Pieper, A.A., Croul, S.E., Zhang, J., Snyder, S.H., Greenberg, J.H., 1999 Post-treatment with an inhibitor of poly(ADP-ribose) polymerase attenuates cerebral damage in focal ischemia. Brain Res. 829, 46-54.

Tapodi, A., Debreceni, B., Hanto, K., Bognar, Z., Wittmann, I., Gallyas Jr., F., Varbiro, G. Sumegi, B., 2005. Pivotal role of Akt activation in mitochondrial protection and cell survival by poly(ADP-ribose)polymerase- 1 inhibition in oxidative stress. J. Biol. Chem. 280, 35767-35775.

Thiemermann, C., Bowes, J., Myint, F.P., Vane, J.R., 1997. Inhibition of the activity of poly(ADP ribose) synthetase reduces ischemia-reperfusion injury in the heart and skeletal muscle. Proc. Natl. Acad. Sci. USA 94, 679-683.

Toth-Zsamboki, E., Horvath, E., Vargova, K., Pankotai, E., Murthy, K., Zsengeller, Z., Barany, T., Pek, T., Fekete, K., Kiss, R.G., Preda, I., Lacza, Z., Gero, D., Szabo, C., 2006. Activation of poly(ADP-ribose) polymerase by myocardial ischemia and coronary reperfusion in human circulating leukocytes. Mol. Med. 12, 221-228.

Veres, B., Gallyas Jr., F., Varbiro, G., Berente, Z., Osz, E., Szekeres, G., Szabo, C., Sumegi, B., 2003. Decrease of the inflammatory response and induction of the 
Akt/protein kinase B pathway by poly-(ADP-ribose) polymerase 1 inhibitor in endotoxin-induced septic shock. Biochem. Pharmacol. 65, 1373-1382.

Veres, B., Radnai, B., Gallyas Jr., F., Varbiro, G., Berente, Z., Osz, E., Sumegi, B., 2004. Regulation of kinase cascades and transcription factors by a poly(ADP-ribose) polymerase-1 inhibitor, 4-hydroxyquinazoline, in lipopolysaccharide-induced inflammation in mice. J. Pharmacol. Exp. Ther. 310, 247-255.

Virag, L., 2005. Poly(ADP-ribosyl)ation in asthma and other lung diseases. Pharmacol. Res. 52, 83-92.

Virag, L., Bai, P., Bak, I., Pacher, P., Mabley, J.G., Liaudet, L., Bakondi, E., Gergely, P., Kollai, M. Szabo, C., 2004. Effects of poly(ADP-ribose) polymerase inhibition on inflammatory cell migration in a murine model of asthma. Med. Sci. Monit. 10, BR77-BR83.

Wallis, R.A., Panizzon, K.L., Girard, J.M., 1996. Traumatic neuroprotection with inhibitors of nitric oxide and ADP-ribosylation. Brain Res. 710, 169-177.

Wallis, R.A., Panizzon, K.L., Henry, D., Wasterlain, C.G., 1993. Neuroprotection against nitric oxide injury with inhibitors of ADP-ribosylation. Neuroreport 5, 245-248.

Xiao, C.Y., Chen, M., Zsengeller, Z., Li, H., Kiss, L., Kollai, M., Szabo, C., 2005. Poly(ADP-Ribose) polymerase promotes cardiac remodeling, contractile failure, and translocation of apoptosis-inducing factor in a murine experimental model of aortic banding and heart failure. J. Pharmacol. Exp. Ther. 312, 891-898.

Xiao, C.Y., Chen, M., Zsengeller, Z., Szabo, C., 2004. Poly(ADP-ribose) polymerase contributes to the development of myocardial infarction in diabetic rats and regulates the nuclear translocation of apoptosis-inducing factor. J. Pharmacol. Exp. Ther. 310, 498-504.

Yamamoto, K., Tsukidate, K., Farber, J.L., 1993. Differing effects of the inhibition of poly(ADP-ribose) polymerase on the course of oxidative cell injury in hepatocytes and fibroblasts. Biochem. Pharmacol. 46, 483-491.

Yeh, C.H., Chen, T.P., Lee, C.H., Wu, Y.C., Lin, Y.M., Jing Lin, P., 2006a. Inhibition of poly(adp-ribose) polymerase reduces cardiomyocytic apoptosis after global cardiac arrest under cardiopulmonary bypass. Shock 25, 168-175.
Yeh, T.Y., Sbodio, J.I., Chi, N.W., 2006b. Mitotic phosphorylation of tankyrase, a PARP that promotes spindle assembly, by GSK3. Biochem. Biophys. Res. Commun. 350, 574-579.

Yeh, T.Y., Sbodio, J.I., Tsun, Z.Y., Luo, B., Chi, N.W., 2006c. Insulin-stimulated exocytosis of GLUT4 is enhanced by IRAP and its partner tankyrase. Biochem J. 402, 279-290.

Yu, S.W., Andrabi, S.A., Wang, H., Kim, N.S., Poirier, G.G., Dawson, T.M., Dawson, V.L., 2006. Apoptosis-inducing factor mediates poly(ADP-ribose) (PAR) polymerinduced cell death. Proc. Natl. Acad. Sci. USA 103, 18314-18319.

Yu, S.W., Wang, H., Poitras, M.F., Coombs, C., Bowers, W.J., Federoff, H.J., Poirier, G.G. Dawson, T.M., Dawson, V.L., 2002. Mediation of poly(ADP-ribose) polymerase1-dependent cell death by apoptosis-inducing factor. Science 297, 259-263.

Zambetti, G.P., 2007. The p53 mutation "gradient effect" and its clinical implications. J. Cell. Physiol. 213, 370-373.

Zheng, L., Gong, B., Hatala, D.A., Kern, T.S., 2007. Retinal ischemia and reperfusion causes capillary degeneration: similarities to diabetes. Invest. Ophthalmol. Vis. Sci. 48, 361-367.

Zingarelli, B., Cuzzocrea, S., Zsengeller, Z., Salzman, A.L., Szabo, C., 1997. Protection against myocardial ischemia and reperfusion injury by 3-aminobenzamide, an inhibitor of poly (ADP-ribose) synthetase. Cardiovasc. Res. 36, 205-215.

Zingarelli, B., O'Connor, M., Hake, P.W., 2003. Inhibitors of poly (ADP-ribose) polymerase modulate signal transduction pathways in colitis. Eur. J. Pharmacol. 469, 183-194.

Zingarelli, B., O'Connor, M., Wong, H., Salzman, A.L., Szabo, C., 1996. Peroxynitritemediated DNA strand breakage activates poly-adenosine diphosphate ribosyl synthetase and causes cellular energy depletion in macrophages stimulated with bacterial lipopolysaccharide. J. Immunol. 156, 350-358.

Zingarelli, B., Salzman, A.L., Szabo, C., 1998. Genetic disruption of poly (ADP-ribose) synthetase inhibits the expression of P-selectin and intercellular adhesion molecule-1 in myocardial ischemia/reperfusion injury. Circ. Res. 83, 85-94. 